\title{
PARTICIPAÇÃO SOCIAL ATRAVÉS DOS USUÁRIOS DO SISTEMA ÚNICO DE SAÚDE: o conhecimento e acesso ao serviço de ouvidoria da saúde
}

\author{
Liliany Mara Silva CARVALHO \\ Silvia Regina PAES. ${ }^{2}$
}

\begin{abstract}
${ }^{1}$ Psicóloga, Mestranda pelo Programa de Pós-Graduação Stricto sensu em Saúde, Sociedade e Ambiente pela Universidade Federal dos Vales do Jequitinhonha e Mucuri. Referência Descentralizada no Ministério da Saúde nos programas de provimento Programa de Valorização da Atenção Básica e Mais Médicos. lilianymara@ bol.com.br

${ }^{2}$ Socióloga, Doutora em Sociologia pela Universidade Estadual Paulista Júlio de Mesquita Filho, Mestre em Sociologia pela Universidade Estadual Paulista Júlio de Mesquita Filho, docente na Universidade Federal dos Vales do Jequitinhonha e Mucuri, Departamento de Ciências Biológicas, Diamantina, Brasil. tudapaes@ig.com.br
\end{abstract}

Recebido em: 15/12/2015 - Aprovado em: 05/11/2016 - Disponibilizado em: 18/12/2016

\begin{abstract}
RESUMO:
A Reforma Sanitária e consequente implantação do Sistema Único de Saúde (SUS) trouxe como uma de suas premissas a participação social, principalmente através das leis 8.080/90 e 8.142/90, nesse contexto consideramos a importância dos serviços de ouvidoria da saúde como um canal democrático de participação. O objetivo deste trabalho foi avaliar o conhecimento e experiências dos usuários do SUS sobre a ouvidoria da saúde. Realizou-se pesquisa exploratóriadescritiva com abordagem quanti e qualitativa. Foram entrevistados 30 usuários do SUS provenientes de 15 distintos municípios que compõem a Região de Saúde de Diamantina, MG. As entrevistas foram gravadas. Como resultados obtivemos que $80 \%$ dos respondentes nunca ouviram falar em ouvidoria, $17 \%$ já ouviram falar, mas não sabiam do que se tratava e $3 \%$ já tinham ouvido falar e sabiam do que se tratava. Dos respondentes $81 \%$ relataram que nunca se manifestaram e $19 \%$ relataram algum tipo de manifestação, ainda que informal. Quando perguntados se eles saberiam onde manifestar, caso necessário, $64 \%$ responderam que não, $13 \%$ responderam que procurariam pela secretaria municipal de saúde, $7 \%$ procurariam o prefeito, 3\% citaram a Gerência Regional de Saúde e 3\% recorreriam ao Ministério Público. Concluímos com o desconhecimento da população sobre serviços de ouvidoria da saúde e apontamos a educação popular como uma das saídas possíveis.
\end{abstract}

Palavras-Chave: Participação Social. Ouvidoria da Saúde. Manifestação Popular. Democracia. Educação Popular.

\begin{abstract}
:
The Health Reform and the consequent implementation of the Unified Health System (SUS) brought as one of its premises social participation, mainly through the laws $8.080 / 90$ and $8.142 / 90$, in this context, it is possible to consider the importance of health ombudsman services as a channel democratic participation. The aims of this study were to evaluate the knowledge and experiences of SUS users of the health ombudsman. Held exploratory and descriptive research with a quantitative and qualitative approach, we interviewed 30 SUS users from 15 different municipalities that make up the Health Region of Diamantina, MG. The interviews were recorded. As a result, we obtained that $80 \%$ of them had never heard of the Ombudsman, $17 \%$ have heard, but did not know what it and 3\% had heard and knew what it was. $81 \%$ of the interviewed reported that they never manifested and 19\% reported some type of manifestation, even informal. When asked if they know where to appear, if necessary, $64 \%$ answered no, $13 \%$ answered they would seek the local health department, the 7\% would seek the Mayor, 3\% cited the Regional Health Management and 3\% would resort to Public Ministry. In conclusion, the ignorance of the population on health ombudsman services and pointed out the popular education as one of the possible outputs.
\end{abstract}

Keywords: Social Participation. Health Ombudsman. People's demonstration. Democracy. Popular Education 


\section{INTRODUÇÃO}

Segundo Angelo e Giangrade (1999) a ouvidoria teve sua origem na Suécia, no século XIX, mais precisamente em 1809, com o surgimento da figura do Ombudsman, que preconizava fortalecer os direitos do cidadão diante do poder do Estado, através da fiscalização das leis por parte dos funcionários públicos, garantindo seus direitos na prática. Estendendo mais tarde aos presídios, minorias raciais e, em 1990, chega até os consumidores, ganhando força no sentido de registrar as demandas da sociedade e aperfeiçoar as ações e os serviços.

No Brasil, mais tardiamente aparece a figura do ombudsman (Vismona, 2011). Neste sentido movimentos foram surgindo, demonstrando a importância dos ouvidores e da implantação dos serviços de ouvidoria, surgiram também legislações que legitimavam a importância destes. Os inegáveis avanços foram constatados através da implantação em 1986 da primeira ouvidoria pública do Brasil. A partir de 2006, com o Pacto pela Saúde, acordo firmado entre os três entes federados, gestores do SUS (governo federal, estadual e municipal), estabeleceuse como parâmetro a Política Nacional de Ouvidorias do SUS (Brasil, 2006).

Neste contexto, é que foi criado o Sistema Nacional de Ouvidorias, ou
Ouvidoria Geral do SUS. Segundo Silva (2013) os estados e municípios são estimulados a também implementar serviços de ouvidoria, que devem preferencialmente ser regulamentados por meio de decretos ou portarias e atuar em parceria com os conselhos de saúde e demais segmentos de controle social.

De acordo com Silva (2013) os acessos a ouvidoria podem ter diversos motivos, que vão de pedidos de informações e esclarecimentos de dúvidas a reclamações, elogios e denúncias. Dessa forma uma manifestação única e individual pode culminar, se bem encaminhada, na solução de problemas coletivos e no aprimoramento dos serviços de saúde para toda a população. O funcionamento de uma ouvidoria em saúde acontece por meio das seguintes etapas: escuta, sistematização, análise e encaminhamento das demandas recebidas.

A necessidade de implantação de uma ouvidoria municipal em saúde surge também como ferramenta para o controle social e a gestão pública, sendo o elo entre o cidadão e a gestão, gerando relatórios periódicos que subsidiem a organização para aprimoramento do trabalho fornecido à população local (Oliveira, 2005).

O tema Ouvidoria, foi abordado tanto na $10^{\text {a }}$ (Brasília, 6 a 9 de setembro de 1996) quanto $11^{\mathrm{a}}$ (Brasília, 15 a 19 de 
dezembro de 2000) Conferências Nacional de Saúde, sendo que foi graficamente descrito no relatório final da $12^{\mathrm{a}}$ Conferência Nacional de Saúde (Brasília, 7 a 11 de dezembro de 2003).

O diferencial da Ouvidoria em Saúde como canal democrático que esta constitui é que a mesma é uma possibilidade que não necessita um representante, como por exemplo, nos casos de Conselhos Municipais de Saúde, associações ou outros tipos de políticas democráticas.

Como nos alerta Santos Junior (2012) os Conselhos Municipais de Saúde trazem em seu bojo extrema importância, no entanto, em uma cidadania que se desenvolve numa civilização contemporânea, que é muito relacionada ao individualismo e que constitui novas identidades e sujeitos, os cidadãos começam a emitir demandas individualizadas.

Acreditamos que a investigação da ocorrência ou não de programas com fomento à participação popular insere-se na realidade acadêmica de forma bastante veemente, uma vez que este conhecimento nos proporciona dados que nos levam a intervenções junto à gestão e a população, de formas educativas, informativas, interativas, dentre outras, baseada em dados qualificados.
Segundo Vázquez et al. (2005) alguns estudos analisam os fatores que influenciam os processos de participação social em saúde, porém são escassos aqueles com a finalidade de avaliar os níveis de informação da população que utiliza os serviços. A maioria das publicações encontradas, que tem relação com o processo brasileiro, se concentra fundamentalmente nos conselhos em saúde, além disto são raras as pesquisas que realizam estudos que dizem respeito à participação da população especificamente na gestão dos serviços públicos de saúde em nível local.

Este trabalho tem o objetivo de determinar, por meio das respostas dadas em entrevista, o conhecimento dos usuários de saúde da Região de Saúde de Diamantina sobre o serviço de ouvidoria da saúde e sua utilização.

\section{METODOLOGIA}

O trabalho foi realizado através de entrevista semi-estruturada, com a utilização de técnicas quanti-qualitativas de pesquisa.

As entrevistas foram gravadas utilizando gravador digital Samsung Galaxy S4 e, em seguida, transcritas na íntegra no software Microsof Word 2007 (®Microsoft Corporation. 
O estudo foi desenvolvido na Região de Saúde de Diamantina, que de acordo com o Plano Diretor de Regionalização do Estado de Minas Gerais (PDR) compreende o total de quinze municípios, com extensão territorial de $14.266,1 \mathrm{~km}^{2}$ e população estimada em 174.912 habitantes. Compreende os seguintes municípios: Alvorada de Minas, Carbonita, Coluna, Congonhas do Norte, Datas, Diamantina, Felício dos Santos, Gouveia, Itamarandiba, Presidente Kubitschek, Santo Antônio do Itambé, São Gonçalo do Rio Preto, Senador Modestino Gonçalves e Serro (Minas Gerais, 2010).

A amostra foi definida de acordo com a técnica de amostragem casual simples, que tem por objetivo uma seleção ao acaso. Buscamos garantir que os sujeitos que constituíram a amostra não fossem escolhidos por nenhuma de suas características, os mesmos foram convidados de forma casual, por conveniência, sendo pessoas que estivessem na secretaria municipal de saúde no momento da visita, totalizando 30 respondentes, sendo 2 de cada um dos municípios visitados.

Seriam excluídos indivíduos que não assinassem o Termo de Consentimento Livre e Esclarecido (TCLE), ou o município em que o gestor não assinasse a carta de anuência como município co- partícipe, no entanto, não ocorreu nenhum caso de negativa.

Esta pesquisa atendeu aos princípios éticos e à Resolução 446/2012 (Brasil, 2012), do Conselho Nacional de Saúde, com Parecer Consubstanciado do Comitê de Ética em Pesquisa (CEP) de $n^{\circ}$ 840.133 de 21/10/2014.

\section{RESULTADOS E DISCUSSÃO}

Como objetivo deste trabalho a pesquisa destinou-se a avaliar o conhecimento e experiências dos usuários de serviços de saúde sobre a ouvidoria em saúde. Quando perguntamos aos usuários se eles sabiam o que era um serviço de ouvidoria em saúde, $80 \%$ deles nos responderam que não, que nunca ouviram falar neste tipo de serviço e, consequentemente, não conheciam a sua finalidade; $17 \%$ responderam que já tinham ouvido falar, mas que não sabiam do que se tratava; 3\%, apenas um dos entrevistados, afirmou que já ouviu falar sobre serviço de ouvidora em seu município e que sabia o que significava.

Corroborando aos dados citados acima estudo realizado por Vázquez et al. (2005) de uma maneira geral considerou-se que ainda é limitado o número de informação da população estudada sobre os mecanismos institucionais de participação. O referido estudo tinha como 
um de seus objetivos conhecer se os entrevistados sabiam da existência de mecanismos institucionais de participação social, sendo eles: conselho municipal de saúde, conferências de saúde, caixa de sugestões, disque saúde, ouvidoria da saúde e PROCON, obteve-se como resultado a ouvidoria como o menos conhecido destes, revelando ser este serviço conhecido por apenas $10,5 \%$ da população entrevistada. Além do menos conhecido este também se revelou como o menos procurado, com participação de apenas $0,1 \%$ da população pesquisada.

Um outro estudo, encomendado pela Ouvidoria Geral ao Departamento de Ciências Sociais da Escola Nacional de Saúde Pública Sérgio Arouca ENSP/Fiocruz, realizado com o público que utiliza os serviços das unidades assistenciais da instituição há pelo menos seis meses, demonstrou que 49,2\% dos entrevistados não conhece o serviço de ouvidoria da instituição e 29,6\% não sabem o que é uma ouvidoria (Silva, 2009).

E, por fim, estudo realizado por Backes et al. (2009), ao questionar sobre serviços de ouvidoria, assemelha-se ainda mais aos nossos resultados, já que todos os participantes relatam desconhecer a existência de tal instância. Mediante o resultado os autores destacaram o descompasso e grande distância entre a exigência sob forma de lei e de direito e o que se estabelece como prática efetiva do sistema de saúde. Denota ainda a fragilidade de medidas com o intuito de informar a população sobre a necessidade de participação nos espaços nos quais são tomadas decisões em saúde.

Perguntamos também aos participantes da pesquisa se eles já tinham feito em seu município algum tipo de manifestação, que poderia ser elogio, sugestão, crítica, reclamação, etc. Dos respondentes, $81 \%$ relataram que nunca se manifestaram e 19\% relataram algum tipo de manifestação, ainda que informal.

Dos que manifestaram dois deles realizaram elogios, um realizou reclamação e um deles relatou apenas que já manifestou, mas não quis declarar a finalidade e/ou descrever o ocorrido.

Desde as primeiras entrevistas percebemos uma profunda e generalizada desinformação sobre os serviços de ouvidoria e, embora os participantes fossem oriundos de municípios diferentes, as respostas apresentadas eram muito similares. Os relatos e a simplicidade demonstrada pela população nos provocaram como pesquisadores, pois entendemos que houve situações, de acordo com seus relatos, que eram extremamente graves e que ainda assim, os 
usuários dos serviços de saúde não se manifestaram.

Entrevistamos um pai que esteve por uma semana com o filho na zona rural sentindo intensa dor de cabeça e edema nesta mesma região cada vez mais acentuado. Quando procuravam pelo médico, na cidade, ele sempre o mandava de volta para casa, passado uma semana, depois de muita insistência da família, a criança foi encaminhada para o município próximo de referência e constatada infecção cerebral, sendo necessária intervenção cirúrgica urgente. Ainda assim a família não realizou nenhum tipo de manifestação.

Acreditamos que a maioria da população entende que manifestar seria algo errado, como uma espécie de ingratidão, pensam eles que devem sentirse satisfeitos ao menor serviço oferecido, ainda que não satisfatório.

Outro aspecto que merece destaque é o entendimento sobre as funções dos vários setores que compõem a saúde. A grande maioria julga que não tem do que reclamar porque quando precisam "são bem atendidos", o que demonstra que a população não entende que eles poderiam não precisar destes serviços se anteriormente trabalhos de prevenção, promoção e informação tivessem sido a eles disponibilizados, por si só a ausência destes serviços já seria um motivo de manifestação.

Soratto et al. (2010) intrigados com todos os fatores que estão em jogo no que tange ao controle social realizaram estudo em que pretendiam responder, dentre outras, a seguinte pergunta: por quais razões a população não se manifesta? Essa indagação vai de encontro ao nosso pensamento ao realizar a pesquisa, pois percebemos que mesmo havendo críticas a respeito dos serviços de saúde municipais os sujeitos não procuram se manifestar.

Em estudo realizado por Vázquez et al. (2005) constatou-se que a proporção não desprezível dos entrevistados que afirmaram "não procurar ninguém" nos serviços de saúde poderia indicar uma falta de confiança nos resultados, já que os respondentes acreditam que os serviços não tomam nenhuma providência em relação as demandas apresentadas. Neste mesmo caminho, Valla (1998) afirma que, a utilização dos mecanismos de participação institucionais pode ser uma opção inadequada se a população não acredita que possa levar a mudanças.

Outros autores, tais como Merhy et al. (2004), apontam para o que consideram como o grande nó crítico: por um lado o não compromisso dos trabalhadores e da gestão com as pessoas, tratando-as apenas como uma doença; por outro, as pessoas se 
sentem incapacitadas diante de uma relação assimétrica, razão pela qual se calam e não se manifestam.

Aproximando da explicação encontrada pelos autores acima, acreditamos, mediante os dados das entrevistas, que o maior peso está relacionado a negação do saber popular incutida nos gestores e trabalhadores, o que faz com que o relacionamento estabelecido entre profissionais, gestores e população esteja baseado na técnica, negando as contribuições pessoais de cada sujeito. Segundo Faria (1996, p.14) as informações são normatizadoras, deixando de lado o que realmente interessa à população, negando as subjetividades dos envolvidos nas ações assistenciais.

Sorato et al. (2010) ressalta que há um saber técnico-científico que nega o saber popular, as subjetividades, seja nos encontros individuais ou coletivos, levando o sujeito, adoecido ou não, a não questionar. Segundo o autor toda e qualquer forma de conhecimento dos sujeitos usuários do SUS é menosprezada, assim apenas tem validade o que está posto, a técnica, o científico.

Com os resultados apresentados neste trabalho e nos trabalhos dos demais autores citados acima, nos resta o entendimento de que, passados tantos anos, o que se percebe é uma participação social pouco efetiva e muitas vezes fragilidades nos mecanismos de controle social. Sobre tal Petry e Faria (2010) ressaltam que o controle social dos serviços de saúde representaria um estágio elevado da sociedade organizada, refletindo num real poder da população em interferir e modificar os rumos políticos, planos e programas de saúde. Mediante essa afirmação parece-nos que aí há uma intenção em não informar a sociedade sobre os mecanismos de participação.

Nesse sentido, eis uma questão levantada por Backes et al. (2009): O que é possível / preciso fazer para alterar essa cultura da qual estamos todos impregnados? As duas pontas do sistema se deslocam para lados contrários. De um lado os gestores, a classe política, que tem dificuldades em encontrar estratégias eficazes de informar a população sobre seus direitos. Por outro lado, a população que não se reconhece como co-gestor do sistema.

Por fim perguntamos aos usuários se os mesmos sabiam a quem recorrer em caso de desejarem realizar alguma manifestação, sobre tal obtivemos diferentes retornos, são eles: $64 \%$ responderam que não saberiam a quem ou onde manifestar; $13 \%$ procurariam pela secretaria municipal de saúde; $7 \%$ iriam de encontro ao prefeito; $7 \%$ mencionaram a 
caixa de sugestões; $3 \%$ citaram a Gerência Regional de saúde; por fim, 3\% relataram que iriam recorrer ao Ministério Público.

Mais uma vez ressaltamos o elevado número de pessoas que não sabe onde manifestar e insistimos na importância da educação em saúde, só é possível uma mudança de cultura se ao povo for dada instrução dos mecanismos que se tem. Entendemos a Educação Popular (EP) como um dos caminhos possíveis para a construção de um novo olhar. Os fundamentos da EP se encontram sustentados na pedagogia sistematizada de Paulo Freire, a premissa básica do autor diz que para o ensinoaprendizagem deve utilizar-se de um conjunto de habilidades que permitam a construção do conhecimento a partir da realidade local, ou seja, das pessoas envolvidas. Segundo Cruz et al. (2012) a EP é considerada um instrumento de emancipação social que, ao colocar a cultura no centro de seu processo, atua sobre a representação da comunidade e, consequentemente, com ela age, por meio de ações organizadas geradoras de autonomia.

Introduzir a EP na saúde requer um esforço contínuo, é preciso levar em consideração tanto as práticas populares quanto as experiências dos profissionais que atuam junto às comunidades e aos movimentos populares e sociais. Segundo Brandão (1982) esta prática objetiva participar do esforço das classes subalternizadas para a organização do trabalho político, a fim de abrir caminho para a conquista da liberdade e dos seus direitos.

\section{CONSIDERAÇÕES FINAIS}

$\mathrm{O}$ estudo mostrou a grande desinformação da população sobre um dos mecanismos de participação social, o serviço de ouvidoria da saúde. Além disto concluímos que, para além da ouvidoria, os usuários do SUS também não realizam manifestações em outros tipos de serviços destinados para tal, de forma que ainda é incipiente a manifestação. A não manifestação foi associada neste trabalho a diversos fatores: a população entende que manifestar seria algo errado; a população não entende quando ou porque deveria se manifestar; a população se contenta e sente agradecida por quaisquer serviços oferecidos; há uma falta de confiança nos resultados, ou seja, pensam eles que manifestar não garantirá mudanças, visto o não compromisso dos trabalhadores e gestão com as pessoas, desqualificando o seu saber. Por fim destacamos ainda que a maioria dos respondentes não sabe a quem ou onde recorrer quando precisam manifestar. 
Menos do que concluir e mais do que simplesmente apontar problemas preferimos neste estudo ressaltar que o trabalho é contínuo e que o nosso fazer como pesquisador pressupõe sempre a busca de diálogos possíveis para melhorias constantes. Neste trabalho lançamos mão da Educação Popular proveniente da pedagogia de Paulo Freire como uma das saídas possíveis, mas desde já adiantamos que esta não é única e que cabe a nós a busca de soluções através de demais estudos.

\section{REFERÊNCIAS}

ANGELO, C. F.; GIANGRANDE, V. Marketing de relacionamento no varejo. São Paulo: Atlas, 1999.

BACKES, D. S. et al. O que os usuários pensam e falam do Sistema Único de Saúde? Uma análise dos significantes à luz da carta dos direitos dos usuários. Ciência e Saúde Coletiva, Rio de Janeiro, v. 14, n.3, p. 903-910, mai-jun. 2009.

BRANDÃO, C. R. Lutar com a palavra: escritos sobre o trabalho do educador. Rio de Janeiro: Graal, 1982.

BRASIL. Ministério da Saúde. Portaria n³99, de 22 de fevereiro de 2006b. Divulga o Pacto pela Saúde 2006 consolidação do SUS e aprova diretrizes nacionais do referido pacto. Diário Oficial [da] República Federativa do Brasil, Brasília, DF, 22 fev. 2006. Disponível em: <http://bvsms.saude.gov.br/bvs/saudelegis/ gm/2006/prt0399_22_02_2006.html>. Acesso em: 23 jun. 2015.

BRASIL. Resolução No 466 de 12 de dezembro de 2012. Trata de pesquisas e testes em seres humanos. Diário Oficial [da] República Federativa do Brasil, Brasília, DF, 12dez. 2012. Disponível em: <conselho.saude.gov.br/resolucoes/2012/R eso466.pdf >. Acesso em: 01 jan. 2014.

CRUZ, P. J. S. C.; VIEIRA, S. C. R.; MASSA, N. M.; ARAÚJO, T. A. M. de; VASCONCELOS, A. C. C. P. de. Desafios para a participação popular em saúde: reflexões a partir da educação popular na construção de conselho local de saúde em comunidades de João Pessoa, PB. Saúde e Sociedade, v. 21, n. 4, p.1087-1100. 2012.

FARIA, E. M. Comunicação na Saúde: fim da simetria? Pelotas: Ed. Universitária, 1996. 175 p.

MERHY, E. E. et al. O trabalho em saúde: olhando e experienciando o SUS no cotidiano. São Paulo: Hucitec. 2.ed., 2004. 296 p.

MINAS GERAIS. (Estado). Plano Diretor de Regionalização da Saúde de Minas Gerais. Belo Horizonte: Secretaria de Estado de Saúde de Minas Gerais, 2010.

MINAS GERAIS. (Estado). Ouvidoria Geral do Estado de Minas Gerais. Secretaria de Estado de Saúde de Minas Gerais. Curso de Extensão em Ouvidoria de Saúde. Belo Horizonte, Minas Gerais, 2013.

OLIVEIRA, J. E. de. A ouvidoria brasileira: dez anos da Associação Brasileira de Ouvidores. São Paulo: Imprensa Oficial do Estado de São Paulo, 2005.

PETRY, A. P.; FARIA, L. C. O processo educativo em saúde como prática de Enfermagem junto aos Conselhos Locais 
de saúde para construção do controle social no SUS. Florianópolis: UFSC, 2004. Trabalho de conclusão de curso Programa de Pós Graduação, Universidade Federal de Santa Catarina, Florianópolis, 2004.

SANTOS JUNIOR, A. F. dos. Ouvidoria no Sistema Único de Saúde: É um espaço de gestão democrática $e$ participativa. João Pessoa: UFPB, 112 p. Dissertação (Mestrado Profissional) Programa de Pós Graduação em Gestão de Organizações Aprendentes, Centro de Ciências Sociais Aplicadas e Centro de Educação, Universidade Federal da Paraíba, João Pessoa, 2012.

SILVA, M. V. da. A comunicação nas instâncias de controle social do SUS: O diálogo entre as Ouvidorias de Saúde e o Conselho Distrital de Saúde na AP 3.1 do município do Rio de Janeiro. Rio de Janeiro: FIOCRUZ, 2009. Trabalho de Conclusão de Curso (Especialização) Curso de especialização em comunicação e saúde, Fundação Oswaldo Cruz, Rio de Janeiro, 2009.

SILVA, R. de C. C. da. Possibilidades de atuação das ouvidorias públicas de saúde: um estudo de caso das demandas do Ministério Público em município de pequeno porte. Revista Direito Sanitário, São Paulo, v. 14, n. 1, p. 60-76, mar-jun. 2013.

SORATTO, J. et al. Participação popular e controle social em saúde: desafios da Estratégia de Saúde da Família. Physis, Rio de Janeiro, v. 20, n. 4. 2010.

VALLA, V. V. Sobre participação popular: uma questão de perspectiva. Cadernos de Saúde Pública, Rio de Janeiro, v. 14, n. 2, p. 7-18. 1998.

VÁZQUEZ, M. L. et al. Nível de informação da população e utilização dos mecanismos institucionais de participação social em saúde em dois municípios do nordeste do Brasil. Ciência \& Saúde Coletiva, Rio de Janeiro, v. 10, n. 1, p. 141-155, set-dez. 2005.

VISMONA, E. L. A ouvidoria no Brasil e seus princípios. Revista IMESP, São Paulo, n. 1, dez. 1998. Disponível em: <http://www.imesc.sp.gov.br.htm>. Acesso em: 13 mar. 2011. 